\title{
SLOTERDIJK SOBRE LA VERDAD
}

\author{
Carla Cordua
}

La concepción contemporánea de verdad difiere considerablemente del concepto clásico antiguo de la misma. Esta diferencia es bastante compleja y varía tanto de un siglo al próximo como de un autor a otro. El presente ensayo considera dos posiciones emparentadas y casi contemporáneas, a saber, las de Michel Foucault y de Peter Sloterdijk, tratando más extensamente al último de estos pensadores, que distingue una gran variedad de formas de la verdad. Ambos coinciden en su posición de conjunto: la verdad, que fue concebida como una, absoluta, incambiante y sublime, se entiende ahora como incrustada en el contexto histórico en el que nace y vive. Se presta especial atención a la división de la sociedad en grupos según su relación con la verdad histórica prevaleciente y a los conflictos culturales a que ello ha solido dar lugar.

Carla Cordua. Doctora en Filosofía por la Universidad Complutense de Madrid. Miembro de número de la Academia Chilena de la Lengua. Profesora titular de la Universidad de Chile y directora de su Revista de Filosofía. Profesora emérita de la Universidad de Puerto Rico. Autora, entre otras publicaciones, de El Mundo Ético: Ensayos sobre la Esfera del Hombre en la Filosofía de Hegel (Barcelona, 1989), Wittgenstein: Reorientación de la Filosofía (Santiago, 1997), Luces Oblicuas (Santiago, 1997), Filosofía a Destiempo (Santiago, 1999), Nativos de este Mundo (Santiago, 2004) y Verdad y Sentido en La crisis de Husserl (Santiago, 2004).

* Ensayo presentado el 30 de abril en el Centro de Estudios Públicos, en el marco del seminario "Filosofía” organizado por el CEP.

Estudios Públicos, 111 (invierno 2008). 
$E_{n}$ ma del ser, un proceso circular cerrado sobre sí que no posee ni mundo en torno ni universo exterior. Es un animal singular, viviente, absoluto, al que no le falta nada, lo cual se manifiesta en su forma esférica. El cosmos no es ni creado ni produce nada; la descripción de su suficiencia se puede encontrar al comienzo del Timeo ${ }^{1}$. Esta unidad estrecha y coherente de lo que es, afirmada por la metafísica no sólo en la antigüedad sino, con algunas variaciones, a través de la edad media y hasta entrada ya la modernidad, es un sistema que incluye el modo de verdad que le corresponde. También esta verdad del todo es unitaria, omniabarcante y duradera tanto porque no cambia como debido a que no será sustituida por algo diferente que la supere. La verdad metafísica de lo Uno se manifiesta fugazmente a la visión extática que forma parte de la experiencia mística del sabio que se ha preparado a lo largo de toda su vida para recibir merecidamente la revelación de tal verdad.

La mayoría de los hombres, claro, viven en el error y, aunque en principio podrían desembarazarse de su ignorancia y supersticiones, en general no emprenderán este camino difícil y exigente. La verdad total del cosmos es tan estable, independiente, unitaria, duradera e indestructible como aquello que se muestra en ella. Ambos son estados de cosas que exhiben su orden y belleza imperecederos. Esta visión de la verdad del todo inspirará los ideales morales que ocupan un lugar central en la filosofía de la antigüedad tardía. El cuidado de sí mismo y el conocimiento de sí que los moralistas recomiendan están estrechamente ligados porque lo razonable para el hombre consiste en atenerse al modelo de la naturaleza cósmica.

Aunque la modernidad patrocina el conocimiento científico del mundo no se deshace bruscamente de todos los ingredientes de la metafísica de la unidad heredada. La crítica activa y eficaz de esta idea de verdad comienza en el siglo XVIII. Para Kant, por ejemplo, la tarea de la filosofía consiste en explicitar las condiciones de que depende la verdad del discurso; los límites que éste debe respetar un vez establecido el distingo entre pensar y conocer, o entre los diversos usos de la razón. Pero no es hasta el siglo XIX cuando la filosofía se propone la revisión del ideal metafísico de verdad. Entre los agresivos negadores de la verdad del saber según la tradición, el pensador que ha dejado las huellas más profundas es Nietzsche. La ciencia, el saber y la filosofía en general, todas las formas de la verdad, están pro-

${ }^{1}$ Platón, Timeo, 33 c-d. 
fundamente envueltas con los intereses de la vida que lucha por durar e imponerse sobre lo que se le opone y la limita. En la esforzada batalla en que consiste vivir y ser no hay nada que se deje apartar, colocar sobre un pedestal por encima de los combatientes. La verdad no es más que uno de los instrumentos disponibles para incrementar la vida y el éxito. Es cierto que ya Francis Bacon en el siglo XV había dicho esto de otra manera: a saber, que la verdad tenía una estrecha relación con el poder, que conocer era capacitarse para lograr que la ciencia moderna convirtiera al hombre en dueño y señor de la naturaleza mediante el descubrimiento de los mecanismos de que dependía. Pero lo decía como progresista, que por fe en la humanidad se prometía lo mejor del poder del hombre sobre el curso del mundo. Cuando Nietzsche, cuatro siglos más tarde sostiene que la verdad presta servicios a los partidos que confligen en la historia, ya no espera nada bueno de las relaciones entre la verdad y el poder. La verdad ha sido destronada y no conocemos nada que pudiera reemplazarla.

Es difícil exagerar la influencia ejercida por la crítica de la verdad de Nietzsche sobre el pensamiento reciente. Antes de referirme a Sloterdijk, mencionaré algunas declaraciones de Foucault para introducir el asunto que nos ocupa. Ninguno de estos dos pensadores representa fielmente las convicciones de Nietzsche, pero ambos han aprendido mucho de su obra. De manera que de antemano cabe esperar de ellos que guardarán la distancia que nos separa de la verdad metafísica de la Unidad cósmica. Foucault dice: "La verdad es de este mundo; se produce en él gracias a múltiples coacciones. Y detenta en él efectos regulados de poder. Cada sociedad tiene su régimen de verdad, su 'política general' de la verdad: es decir, los tipos de discurso que acoge y hace funcionar como verdaderos o falsos, el modo como se sancionan unos y otros; las técnicas y los procedimientos que están valorizados para la obtención de la verdad; el estatuto de quienes están a cargo de decir lo que funciona como verdadero". Agregará, en seguida, que en sociedades como la nuestra la 'economía política de la verdad' se caracteriza por cinco rasgos importantes. Son: 1) la verdad está centrada en el discurso científico y las instituciones que lo producen; 2) está sometida a una constante incitación económica y política porque es necesaria tanto para la producción económica como para el ejercicio de la política; 3) es objeto de una inmensa difusión y consumo en el cuerpo social; 4) es producida y trasmitida bajo el control no exclusivo pero dominante de grandes aparatos políticos o económicos: universidades, ejércitos, escritura y medios de comunicación; 5) la verdad es lo que provoca los debates políticos y los enfrentamientos sociales llamados 'luchas ideológicas'”2.

\footnotetext{
${ }^{2}$ Foucault, M.: Un Diálogo sobre el Poder, 1985, pp. 143-44.
} 
Foucault, crítico de la pervivencia de nociones antiguas acerca de la verdad en la historia de la filosofía, dice: "La filosofía occidental... ha caracterizado siempre al conocimiento por el logocentrismo, por la similitud, la adecuación, la beatitud, la unidad. Todos estos grandes temas están puestos ahora en cuestión”. Inspirándose en Nietzsche y su crítica de la verdad, sostiene: "Si uno quiere conocer realmente el conocimiento, saber lo que es, aprehenderlo de raíz, en su fabricación, uno debiera acercarse no a los filósofos sino a los políticos, debiera comprender cuáles son las relaciones de lucha y poder. Solamente en estas relaciones de lucha y poder, por la manera en que las cosas entre ellas y los hombres entre sí se odian, luchan, tratan de dominarse unos a los otros, se esfuerzan por ejercer unos sobre los otros relaciones de poder, es que uno comprende en qué consiste el conocimiento”. Foucault reconoce que: "hay en Nietzsche un cierto número de elementos que ponen a nuestra disposición un modelo para el análisis histórico de lo que yo llamaría la política de la verdad”3. Prosigue sosteniendo que "El conocimiento es al mismo tiempo lo más generalizante y lo más particular que existe. El conocimiento esquematiza, ignora las diferencias, asimila las cosas entre ellas, y lo hace en verdad, sin fundamento alguno. De esta manera el conocimiento es siempre un desconocimiento. Por otra parte, es siempre algo que enfoca malvadamente, insidiosa y agresivamente a los individuos, a las cosas, a las situaciones. No hay conocimiento sino en la medida en que entre el hombre y lo que conoce se establece, se trama algo así como una lucha singular, un tete a tete, un duelo. Siempre hay en el conocimiento algo que pertenece al orden de los duelos que hace que él sea siempre singular. Este es el carácter contradictorio del conocimiento, tal como está definido en los textos de Nietzsche..." nes políticas en la sociedad servirían para abordar el problema de la formación de cierto número de campos del saber a partir de ellas.

Sobre la variedad de los campos del saber y de los resultados de la investigación en las sociedades modernas, se dice: "Ya no hay para la ciencia un objeto total, ni una naturaleza, un cosmos, un universo, y, en la hora actual, no hay ya una ciencia sino ciencias, esto es, aspectos extremadamente especializados que establecen técnicamente su verdad. Pero es en esta totalidad evacuada por las ciencias donde estamos nosotros, donde existimos, donde estamos envueltos" ${ }^{5}$. Una falta grave que impide concebir adecuadamente las varias funciones sociales de la verdad es, según Foucault, la suposición que "el sujeto humano, el sujeto del conocer, y las

\footnotetext{
${ }^{3}$ Foucault, M.: Dits et Écrits I, 1954-1975, 2001, pp. 1417-1418.

${ }^{4}$ Ibid., p. 1420.

${ }^{5}$ Citado en Foucault, Dits et Écrits I..., pp. 481-482.
} 
formas mismas del conocimiento son de alguna manera dadas anticipada y definitivamente, y que las condiciones económicas, sociales y políticas de la existencia no hacen otra cosa que depositarse e imprimirse en el sujeto definitivamente dado". Mi propósito, declara, es mostrar que "las prácticas sociales pueden, al establecerse, engendrar campos del saber que no solamente hacen aparecer nuevos objetos, nuevos conceptos, nuevas técnicas sino que también generan formas totalmente nuevas de sujeto y de temas del conocimiento. El mismo sujeto del saber tiene una historia, la relación del sujeto con el objeto, o dicho más claramente, la verdad misma tiene una historia"6.

\section{II}

Al ocuparse de la cuestión de la verdad Sloterdijk se inspirará en la teoría heideggeriana de la apertura de la existencia humana al mundo. En su constitución fundamental el hombre es abierto a lo que hay allí donde está y el espacio mundano es claro y deja ver lo que allí se encuentra. La apertura y el claro son partes principales de la idea de verdad de Heidegger. "Las meditaciones de Heidegger para determinar de nuevo 'la esencia de la verdad', son reflexiones que toman su punto de partida en la palabra griega alethéia, lo no oculto, lo no escondido, para ver en ella una indicación del paso de lo oculto al lado diurno de los entes"7. Esta interpretación de la verdad como desocultamiento le asigna un lugar en el orden fenoménico. La verdad en su sentido primordial es una posibilidad inseparable del hombre: ella le ocurre dinámicamente, sucede en el tiempo, es un ir y venir entre lo escondido y lo manifiesto ${ }^{8}$. De la humanidad capaz de verdad se dirá, entonces, que es a la vez extática sin dejar de ser íntima. Esta doble condición de poder estar fuera de sí y adentro consigo es lo que hace posible que el hombre tenga mundo, una exclusividad que no comparte con nadie. Sloterdijk conservará en su obra estos aportes originales de Heidegger.

Sloterdijk se separa, en cambio, del maestro adoptando un punto de vista antropológico naturalista, que Heidegger rechaza por considerarlo incompatible con la fenomenología de la existencia humana. Critica a Heidegger porque se detiene en la idea de verdad como revelación de lo escondido, sin explicar cómo llegó el hombre históricamente a tener esta capacidad de conocer la verdad que informa cabalmente la vida humana. Sin considerar esta discusión examinamos lo que Sloterdijk propone sobre la esfera

\footnotetext{
${ }^{6}$ Foucault, Dits et Écrits I..., 2001, pp. 1406-1407.

${ }^{7}$ Sloterdijk, Peter: Sphären, 1998-2004, III, p. 218.

${ }^{8}$ Sphären, III, p. 428.
} 
histórico-cultural de la verdad que no falta nunca en la vida humana. Ocuparse de la verdad es referirse "al lugar donde las cosas se vuelven manifiestas y también decibles o representables"9. La verdad nunca existe en estado puro o aislado sino que coexiste necesariamente con el error. Quien se ocupa o posee una verdad corre el riesgo de participar de los errores de alguna manera asociados a ella: aunque éstos sólo aparecen más tarde son siempre de temer. En este sentido, la posesión de una verdad que comprendemos y conserva su vigencia no es un refugio que proteja del error.

Los hombres guardan las verdades que conocen. Desde esta perspectiva la verdad se parece a un granero. Pero considerando que ella nos expone a errores, el lugar de la verdad también es similar a un vertedero, sostiene Sloterdijk. "En el granero se acumula lo que se acredita como valioso... Al vertedero se arroja, en cambio, lo que el grupo no puede o no quiere conservar, lo que es inútil o nulo. Verdadero es aquello que se guarda para volver a valerse de ello. La imagen del granero permite asociar a las verdades, antes de que se conviertan en objetos de colección y de cuidado, con una cosecha originaria que las junta para guardarlas” ${ }^{\prime 10}$. La verdad que acontece históricamente aparece siempre ligada a un sitio habitado por hombres de una manera característica para el grupo que vive en él. Su manifestación estará ligada al 'genio del lugar'. "En cuanto localización 'en la que ocurre', donde 'surge', donde ella 'se prueba', donde 'alguien la enuncia', donde uno 'deja que se la digan', donde lo dicho no puede ser reconvertido en no dicho, donde lo conocido y revelado es conservado y difundido, y en la cual tal vez mucho, acaso la mayor parte, queda latente y sin enunciar, el lugar de la verdad acoge a sus habitantes en su claroscuro y los somete a la tensión de honrar a la verdad como debe ser. Lo que se sabe con seguridad exige ser retenido en su validez mientras que lo inseguro, lo no develado pero que posiblemente lo será en adelante, proyecta una media luz y obliga a la cautela"11.

Sloterdijk describe el proceso durante el cual segmentos de aquello que estuvo sustraído al conocimiento van pasando a formar parte de éste y lo liga tanto al tiempo como al espacio habitado por un grupo cultural. Por ejemplo, los pueblos que inventaron la investigación científica de la naturaleza en la modernidad pueden distinguir entre los fenómenos que aparecen desde sí y aquellos que han sido obligados a manifestarse mediante operaciones técnicas de búsqueda de lo escondido o desconocido. Un caso de mostración forzada resulta de las prácticas de la cirugía, que, aparte de sus

\footnotetext{
${ }^{9}$ Sphären, III, p. 429.

${ }^{10}$ Sphären, III, pp. 429-430.

${ }^{11}$ Sphären, III, pp. 430-431.
} 
funciones curativas, exhiben la interioridad de los cuerpos, que no había sido observada antes de tales intervenciones. En general sabemos que las técnicas modernas de investigación no esperan pasivamente la manifestación de las cosas y las condiciones que le interesan, sino que las apremian a mostrarse mediante agresivas interrogaciones y experimentos ${ }^{12}$.

El mundo como espacio iluminado se ofrece a los que han encontrado en él un lugar habitable para revelarles ciertas verdades. Pero los habitantes perciben inmediatamente con certeza que no todo está iluminado. Sólo la parte más pequeña de todo lo que existe es accesible al saber actual y la percepción. "La esfera clara a la que hemos salido es un punto luminoso circundado por lo desconocido, no manifiesto, no dicho, no pensado. En esto que se sustrae, se esconde, según convicción de los antiguos, lo ontológicamente esencial, aquello de cuya exploración se ocuparán los sabios, esas inquietantes personas que comparten la esfera de nuestra existencia. La sensibilidad de los hombres para la verdad se desarrolla a partir de la intuición según la cual hay un intercambio difícil de captar en la frontera entre estos dos reinos del ser: el clarificado y el oscurecido"13.

Sloterdijk se dedicará principalmente a caracterizar el lugar donde la verdad sucede y la manera cómo existe allí esa parte de sus habitantes que la conoce. Desde lo desconocido que rodea e invade el espacio habitado, proceden, en determinadas circunstancias, ciertas novedades que se incorporan a lo sabido de lo que se suele hablar. En dirección contraria, algunas de las cosas sabidas caen en el olvido o se incorporan a lo implícito, a aquello que la vida del grupo da por descontado, pierde de vista y desconsidera como si no existiera. De este proceso, que tiene dos direcciones que atraviesan la frontera divisoria entre lo explícito y lo implícito, se sigue que la verdad no es la existencia determinada de cierto estado de cosas que pueda considerarse como estable y permanente; ni tampoco una propiedad definida de las proposiciones. Más bien es un ir y venir ${ }^{14}$, el nexo entre una iluminación actual y un hundimiento en la noche atemática. En la medida en que lo presente, al parecer siempre igual, acapara toda la atención, perdemos de vista el carácter dinámico y situado del suceder de la verdad. A propósito de la dificultad que ha tenido la filosofía para hacerse cargo del carácter temporal de la verdad, Sloterdijk les dedica un recuerdo a los dos filósofos que nos enseñaron a verla como algo que acontece: "El vuelco de

12 Sloterdijk, Peter: Sphären, 1998-2004, III, pp. 80-81 n; cf. Sloterdijk, P. y Peter Weibel: Der ästhetische Imperativ: Schriften zur Kunst, 2007, pp. 396-397.

${ }^{13}$ Sphären, III, pp. 427-428.

${ }^{14}$ Sphären, III, p. 428. 
la mirada sobre la temporalidad de la verdad que hacía falta, recién vinieron a darlo pensadores como Hegel y, más aún, Heidegger, aunque no discutimos aquí si con ello lograron resultados satisfactorios”"15.

\section{III}

Sloterdijk admite muchos tipos de verdad y funciones vitales diversas en las que a ésta le cabe un papel decisivo. En este sentido, cultiva el análisis filosófico de casos y formas de verdad que no fueron mencionadas tradicionalmente, para agregarle extensión, precisión y complejidad al tema.

Desde un punto de vista pragmático, la receptividad para la diferencia entre lo verdadero y lo falso está ligada a la experiencia de determinadas acciones y proposiciones que pueden ser tanto acertadas como desacertadas y falsas. Sostener que los hombres dependen del éxito de sus acciones y de sus proposiciones significa comprobar que pueden ser confundidos por los valores de la verdad. Sloterdijk cree que ocurre así ya en un nivel biológico. La seguridad procedente de hacer decisiones acertadas y la confiabilidad de las expresiones verbales pueden ser, desde un comienzo, cosas de vida o muerte. Las complejas relaciones entre lo claro y lo escondido configuran sucesos que ocurren, se revelan y dan que pensar. Pero la diferencia entre las proposiciones verdaderas y las falsas se funda sobre acciones que son exitosas, adecuadas y conducentes o, por el contrario, fracasadas, inadecuadas e inconducentes. Es así como el mundo manifiesto se da desde siempre de dos maneras diversas: una de ellas depende de la conexión de nuestras acciones; y la otra, del tejido de los sucesos que nos afectan. El doble sentido de la verdad como develamiento del éxito de la acción adecuada, por una parte, o como la enunciación de la proposición apofántica, por la otra, ha sido reconocido por los hombres desde siempre.

Además de las verdades destinadas a ser publicadas y compartidas socialmente, Sloterdijk analiza algunas formas de la verdad ligadas a la intimidad de la existencia personal. A la luz de las Confesiones de San Agustín, el filósofo examina un tipo de discurso cuyo propósito principal es la exposición de la propia intimidad ${ }^{16}$. Aunque la obra también contiene disertaciones, se vale de las formas literarias establecidas de la oración y la confesión para la revelación veraz de la intimidad. Estas dos formas de expresión del penitente calan más hondo que la manifestación forzada de la verdad a la que eran sometidos mediante torturas los esclavos sometidos a juicio en la

\footnotetext{
${ }^{15}$ Sphären, III, p. 428.

${ }^{16}$ Sphären, I, pp. 558ss.
} 
antigüedad. La confesión religiosa en el sacramento de la penitencia parece ser más fecunda para la promoción de la verdad que las confesiones obtenidas a la fuerza por un tribunal, pues aquella se formula en la esperanza de ser acogida con misericordia, mientras que, bajo tortura, la motivación de callar o de deformar acciones propias y ajenas no cesa nunca. En la confesión del penitente "la mentira sería un contrasentido, porque la idea misma de la confessio se basa sobre la comprensión de la ventaja de decir la verdad. El premio de la confesión consiste en que quien dice la verdad, llega a 'estar-en-la-verdad'”17.

Descontento de verse entre quienes se ocupan sólo de la verdad de las representaciones y de los enunciados verbales, Sloterdijk explora brevemente otras acepciones de verdad nunca examinadas por la filosofía. Entre ellas, las llamadas "verdades de analfabeto"18, y la verdad relacionada con el comer y la incorporación de alimentos, entre otras. Dice: "En este concepto de verdad no se trata de la presentación o representación de una cosa en otro medio, sino de la incorporación o integración de una cosa en otra. Es obvio que aquí chocan dos modelos distintos de la adecuación que posibilita verdades. Mientras que la verdad de la representación que es generalmente reconocida y respetada, trata de una adecuación entre el intelecto y la cosa o de la proposición y el estado de cosas mentado, la verdad más bien despreciada de la incorporación apunta a la adecuación del contenido al receptáculo o del

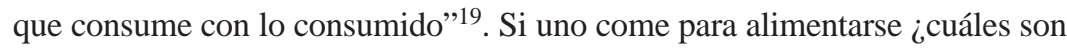
los alimentos verdaderos? Los ejemplos de Sloterdijk son numerosos y de muy diversos tipos. Para nosotros, este intento de incluir otras acepciones de verdad en sus exploraciones resulta interesante pues otros pensadores suelen detenerse en breves declaraciones sobre vastos problemas apenas dan con una posición que parece poder resolverlo todo.

Con el distingo entre legos y expertos —o peritos como solía decirse en castellano- Sloterdijk designa una separación social válida para todos los grupos humanos. Las varias funciones que en las sociedades cumplen aquellos que saben o son peritos las han desempeñado en diversas situaciones históricas los siguientes tipos de personas: los chamanes, los sacerdotes, los profetas, los visionarios, los escritores, los filósofos y los científicos. Su contraparte lega o ignorante comprende a los miembros sencillos de la tribu, a los analfabetos, los pacientes, los creyentes, los empíricos, los lectores de periódicos y los aficionados a las competencias por televisión, sostiene Sloterdijk. Nunca ha habido un pueblo que no desarrolle al menos

\footnotetext{
${ }^{17}$ Sphären, I, pp. 559-560.

${ }^{18}$ Sphären, I, p. 532ss.

${ }^{19}$ Sphären, I, p. 532.
} 
rudimentariamente un "sistema bicameral" de acceso a la verdad. "El primer componente de este sistema constituye una Cámara de Conocimientos Comunes cuyos miembros son los conocedores de lo ordinario; el segundo, una Cámara de los Lores Cognitivos que reúne a quienes saben más, los magos, los expertos, los profesores" ${ }^{20}$. Pero desde el comienzo de las culturas llamadas "superiores" este ordenamiento ha cristalizado en instituciones que distinguen entre legos y sapientes "como entre dos pueblos distintos al interior de una misma población”21.

Esta división interna de la vida social a propósito de los grados en que sus miembros poseen verdades y pueden acceder a otras, división que, según Sloterdijk, constituye un rasgo humano omnipresente, necesita algunas explicaciones genéticas. El filósofo ofrece las siguientes: la alta cultura y aquella que dispone de una escritura fueron consideradas como idénticas durante los tres primeros milenios desde la invención de la escritura. Se trata de un tiempo en el que unos pocos tienen el monopolio de la escritura mientras que los muchos son analfabetos. Esta división se conserva, aunque algo cambiada, después de la alfabetización generalizada. Tanto las culturas como las artes se dividen ahora de nuevo entre las altas y las bajas: "Todavía al comienzo de la modernidad europea, cuando Francis Bacon formuló el programa de una 'sociedad' investigadora y progresista, le dedicó un monumento al lugar de la verdad. Pues también en el estado modélico de la Nueva Atlántida hay una institución superior del saber, una universidad de elite, dedicada sólo al progreso, llamada la Casa Salomón, cuyos miembros eran obligados, tal como en una orden caballeresca cognitiva, a guardar estricto silencio acerca de ciertos conocimientos no publicables"22. De manera que el acceso a las verdades más exquisitas está reservado a los expertos, quienes demostrarán constantemente su superioridad frente a los portadores del saber más ordinario, estableciendo así una nobleza de derecho propio.

Sloterdijk estudia las luchas históricas entre facciones de expertos y legos, y las describe como verdaderas logomaquias. Se trata de una rivalidad constante alrededor de la verdad y de las formas legítimas de su enunciación, acerca de lo que aparenta ser saber y el saber auténtico, acerca de los verdaderos y los falsos profetas. Ejemplos históricos de tales enfrentamientos son el ataque político-metódico que Platón lanza contra los sofistas de Atenas para privar de legitimidad a la formación de opiniones sobre la base de meras verosimilitudes; la ofensiva religioso-política de Diocleciano contra los adivinos, intérpretes de signos y astrólogos durante el imperio

\footnotetext{
${ }^{20}$ Sphären, III, p. 431.

${ }^{21}$ Sphären, III, p. 432.

${ }^{22}$ Sphären, III, p. 432.
} 
romano. Casos posteriores del mismo conflicto encuentra el filósofo en las polémicas entre creacionistas y evolucionistas sobre el comienzo de la vida en la tierra; en los alegatos críticos contra las ideologías durante el siglo XIX; en el intento de destitución de la filosofía por el positivismo declarando que los problemas filosóficos son problemas ilusorios; y también en la acusación reciente de que la filosofía, en su época de decadencia, habría condescendido a ocuparse de la vida cotidiana.

Las primeras formas del futuro universalismo de la filosofía y de las ciencias, aparecen en la Grecia antigua cuando filósofos y científicos dejan de ser encarnaciones de la sabiduría popular y forman colectivos, escuelas y movimientos indiferentes a las comunas de las que proceden originalmente sus representantes. Se organizan como un grupo de inteligencias separadas. Forman castas de expertos en materias lógicas y morales, que mantienen relaciones mucho menos estrechas con sus connacionales que con extranjeros igualmente aislados y tan abstraídos como ellos, que comparten sus intereses. "De este efecto surge ya en la antigüedad europea y asiática la Internacional de los Portadores del Conocimiento Superior. Ella constituye el primer movimiento ecuménico, formado por lógicos desterritorializados, por profesores de ética que son patriotas de la humanidad o por ascetas que le vuelven la espalda al mundo"23. Allí se genera el fenómeno del pacifismo meditativo o académico, la ficción de una existencia desinteresada, comprometida exclusivamente con la 'verdad pura', que cree poder desentenderse de las fabricaciones del saber partidista, como si su defunción social la hubiese purificado. "Del axioma pacifista de la academia surge 'la libertad cabal... en el juego de los argumentos y contraargumentos'. Con razón se pudo afirmar en consecuencia que 'el alma de la ciencia es la tolerancia'”24, concluye el filósofo con ironía, después de haber descrito el engreimiento y la agresividad de los expertos.

El modo de inserción de los portadores del conocimiento superior en su grupo social es descrito más de una vez por Sloterdijk. Pertenecen separados o se separan sin abandonar el grupo, se podría decir. El aislamiento de filósofos y científicos es casi completo y su soledad y falta de participación en la comunidad los asimila, para sus contemporáneos, a la esfera de los muertos del grupo. Este último siente que "los que saben son una especie de muertos vivos que están más cerca de los números y las estrellas que de sus conciudadanos" ${ }^{\text {25 }}$. La separación entre el grupo social y sus autoridades cognitivas se debe en parte a las desmedidas pretensiones de éstas:

\footnotetext{
${ }^{23}$ Sphären, III, p. 436.

${ }^{24}$ Sphären, III, pp. 435-436.

${ }^{25}$ Sphären, III, p. 436.
} 
"La soberbia de los que saben escribir es uno de los hechos más poderosos de la historia de la civilización”26. Un ejemplo de ello, dice el filósofo, se encuentra en el desprecio de Heráclito hacia los que no saben lo que él sabe. Pero el aislamiento de los representantes de la verdad es también una condición de la que depende la fundación primera de la filosofía y la ciencia como actividades con características propias. Filósofos y científicos rompen con los ídolos de la tribu, se separan de la caverna y del mercado, y su conciencia de sí y de sus tareas dependen de esta ruptura. De manera que Sloterdijk puede afirmar que la condición fundacional de la ciencia es su asocialidad, que presupone la transformación del científico, que dejará de ser un ciudadano para convertirse en un extranjero que, en el nombre de una verdad, se dirige a los legos para hablarles de planetas, de triángulos, de animales submarinos y de tumores. Como delegado de verdades externas y trascendentes, el científico puede ganar autoridad en el colectivo, y a veces, protegido por los poderosos, alcanzar poder en él. "Por eso la ciencia siempre rompe sólo pro forma con el cuarto tipo de ídolos, los del teatro. Ella en verdad incrementa el número de los ídolos del teatro y reclama escenarios para sí en los que se llevan coturnos más altos que en ninguna otra parte"27.

\section{IV}

En el siglo XX los discursos científicos y filosóficos se dividen en cientos de disciplinas y especialidades de derecho propio. Casi cualquier asunto llega a ser objeto de una '-logía' que pretende incorporarse al lugar de la verdad. Esto es parte de la crisis permanente que afligió al siglo pasado tanto en Europa como en Asia. Nada consiguió cambiar las relaciones arquetípicas entre expertos y legos, sostiene el pensador. Aunque la población se ha tornado relativamente escéptica acerca de la filosofía y la ciencia, subsisten las dos Cámaras mientras la fe en la ciencia sigue palideciendo. Cunde, en cambio, la impresión de que ya ni la verdad es lo que solía ser. La institución científica ha perdido, entre el siglo XVII y el XX, lo que la sostuvo antes. Bacon creyó con ingenuidad evangélica, sostiene el filósofo, en la alianza natural de la ciencia y el progreso humano. La época de vigencia de este paradigma terminó. No sólo la creciente corrupción de los expertos sino el surgimiento del complejo científico-militar durante la primera guerra mundial a los dos lados del Atlántico, acabaron hundiendo las esperanzas humanísticas en relación con el conocimiento. Este proceso culmina con el

\footnotetext{
${ }^{26}$ Sphären, III, p. 432.

${ }^{27}$ Sphären, III, p. 437.
} 
compromiso de la física moderna en los ataques atómicos de agosto de 1945 contra Japón. Las ciencias perdieron la independencia y la inocencia; la desconfianza que inspiran ha invadido la cultura superior y, por otro lado, la investigación científica se vuelve cada vez más esotérica. El futuro de estas relaciones entre la sociedad y el saber, de las que depende el ámbito de la verdad, es difícil de pronosticar en tales circunstancias.

Otra fuente de la desilusión moderna con el conocimiento de la verdad se alimenta, según Sloterdijk, de la crítica y el desenmascaramiento de la 'voluntad de saber'. Quienes no se contentan con el mezquino empirismo y racionalismo del saber, dirán que al final se encuentran tan ignorantes como eran cuando comenzaron a aprender. "Al término de la gran voluntad de saber se halla siempre por fuerza la 'desesperación teórica'; le quema el corazón al pensador cuando comprueba que no podemos saber lo que 'verdaderamente' queremos saber”28. Nietzsche y el pragmatismo subrayarán después que la voluntad de saber está alimentada por la voluntad de poder. "El impulso a sobrepasar el límite es más fuerte que la comprensión de los límites de nuestro conocimiento"29. El saber mismo no es capaz de saciar la voluntad de saber, cuyo impulso es desmesurado desde la raíz, porque detrás de cada conocimiento se acumulan nuevos enigmas. Necesaria y universalmente, el saber busca saber más. "El querer saber es un derivado del deseo de poder, del afán de desarrollarse, durar, del apetito sexual, el deseo de placer, de disfrutar de sí y distraerse de la necesidad de morirse. Lo que es considerado como ilustración teórica e investigación no puede alcanzar objetivamente sus pretendidos propósitos, pues estos no pertenecen a la esfera teórica”30.

La conexión de la verdad con el error, que no puede ser evitada, lleva a Sloterdijk a compartir la convicción de que el hombre vive siempre en la 'errancia'. Tanto al individuo como al grupo le pasa que precisamente aquello que ilumina algo, esconde otra cosa o circunstancia. La verdad nunca se consigue de buenas a primeras, sino sólo en un segundo intento, como producto de la crítica que destruye lo que antes parecía ser el caso. La verdad no se "descubre" inocuamente y sin batalla, sino sólo después de triunfar batallando contra sus antecesoras, que la enmascaraban y se le oponían. "Apenas la mirada desconfiada de la investigación penetra el mundo, ve que está que revienta sus costuras debido a sus problemas, peligros, engaños y abismos. En el universo del conocimiento moderno predominan los bastidores, los suelos dobles, los panoramas, las imágenes engañosas,

\footnotetext{
${ }^{28}$ Sloterdijk: Kritik der zynischen Vernunft, 1983, I, p.338.

${ }^{29}$ Ibid.

${ }^{30} \mathrm{Ibid}$.
} 
los gestos torcidos, los sentimientos secretos, los motivos ocultos, los cuerpos envueltos”31. Estos son fenómenos que dificultan el acceso a la "realidad misma", precisamente porque ésta, a medida que se torna más compleja, consta de acciones y signos ambiguos. Esto obliga a separar lo manifiesto de lo escondido. "Soy engañado, por tanto soy. Desenmascaro engaños, engaño yo mismo, por tanto me conservo. También así se puede traducir el cogito ergo sum cartesiano"32. Motivos de todas clases preceden a la búsqueda de "verdades desnudas sobre hechos desnudos": tal vez ya sabemos demasiado para bien de nuestra salud, sospecha el Sloterdijk nietzscheano Recibimos un entrenamiento "ilustrado" que domina toda la época. La desconfianza y el racionalismo nacen de los mismos impulsos; nos invade la necesidad abrumadora de una certeza absoluta. Los errores deben acabar tornándose trasparentes, mediante las maniobras adecuadas: Verum et fictum convertuntur. Sloterdijk cree, en cambio, que "aquello que en este mundo se puede dar por descontado es el ser engañado, la amenaza, el peligro y no lo abierto (Offenheit), la oferta, la seguridad”33.

\section{V}

Para terminar recordamos que Sloterdijk admite, con Hegel y Heidegger, la idea de una historia de la verdad. Ello viene a ser una consecuencia del dinamismo, de la historicidad, que estos dos filósofos introducen en una tradición que alojaba a la verdad en una fortaleza inmune al tiempo y al cambio. El crecimiento enorme del conocimiento y de la técnica, ¿puede seguir siendo interpretado — pregunta Sloterdijk — como prefiere hacer Heidegger, quien continúa entendiéndolo, después de dos siglos y medio de metafísica y técnica europeas, como los envíos del destino a la errancia de los hombres? ? $^{34}$

"Con la iniciación de la modernidad la verdad misma parece haber entrado en la época en que se torna posible descubrirla artificialmente. Desde este momento en adelante puede haber y necesariamente hay investigación, que es el robo organizado que se le hace a lo oculto"35. Ilustran la idea de una historia de la verdad y las variaciones que señalan a sus diversas épocas tanto los descubrimientos científicos que son el producto de la experimentación como la empresa de Portugal y España que culmina en la

\footnotetext{
${ }^{31}$ Kritik der zynischen Vernunft, II, p. 604.

32 Ibid.

${ }^{33}$ Kritik der zynischen Vernunft, II, p. 604.

${ }^{34}$ Cf. Sloterdijk: Nicht gerettet, 2001, pp. 214-215.

${ }^{35}$ Sloterdijk: Im Weltinnenraum des Kapitals, 2005, pp. 154-155.
} 
circunvalación de la tierra y los descubrimientos de un mundo nuevo en el siglo XVI. "El nombre 'época de los descubrimientos' es un plural que designa un suceso singular, el super-acontecimiento auténticamente histórico de la vuelta a la redondez de la tierra y su captación. El sentido de este plural menciona la summa de las prácticas mediante las cuales lo desconocido se transforma en conocido, lo irrepresentado en representado"36. "La esencia de la era de los descubrimientos quedó determinada por la forma empresarial de la expedición: se descubre porque se busca y se busca porque se sabe en qué región se podría encontrar... La expedición es la forma rutinaria de lo que se organiza como empresa de buscar y encontrar. Debido a ello, el movimiento decisivo de la globalización no es sólo un caso de expansión territorial; sino que pertenece al proceso central de la moderna historia de la verdad"37.

Una historia de la verdad, reclama Sloterdijk, tendría que ser exitosa y, en la medida en que lo fuese, se ocuparía del saber eficaz y de la capacidad sapiente y de su aparente dominio y aplicación por los hombres. "Pero es, al mismo tiempo, evidente que ella no puede ser sino una historia parcial de la verdad (eine Teilgeschichte der Wahrheit), pues su captación por los hombres y las empresas será siempre fragmentaria”38. En vez de ligar la historicidad de la verdad al problemático conjunto del saber humano, Sloterdijk prefiere verla asociada a acontecimientos decisivos que inauguran épocas del proceso histórico, afectando por igual al hombre y a su mundo. Somos criaturas adventicias, seres que siempre están llegando y a quienes les llega algo que los transforma a ellos mientras llega y también después de haber terminado de llegar. Esta ubicación concreta de la verdad en el descubrimiento fáctico, abre la posibilidad de abordar la cuestión, no como un asunto universal que presupone todas las verdades formando un solo racimo actual, sino como una revelación singular, fechable y ubicable, que, por el alcance de sus consecuencias, transforma tanto al mundo como a sus habitantes. Para captar esta perspectiva es preciso no sólo admitir la historicidad de la verdad sino también y al mismo tiempo, la del hombre que la hace, la formula y la recibe. Radicalmente, nuevas verdades, mundo nuevo, nuevos hombres. En el Espacio Interior del Mundo del Capital: Una Teoría Filosófica de la Globalización (2005) de Sloterdijk contiene un capítulo titulado "Expedición y verdad"39 en el que la verdad que ocurre, y cuyas consecuencias inauguran un mundo nuevo, es el descubrimiento de las

\footnotetext{
${ }^{36}$ Im Weltinnenraum des Kapitals, p. 153.

${ }^{37}$ Im Weltinnenraum des Kapitals, p. 152.

${ }^{38}$ Nicht gerettet, p. 216.

${ }^{39}$ Im Weltinnenraum des Kapitals, pp. 151-156.
} 
Américas por algunos europeos que se hacen a la navegación completamente equivocados acerca del planeta Tierra, y de las relaciones que hay en él entre la tierra firme y las aguas oceánicas.

\section{BIBLIOGRAFÍA}

Platón: Timeo.

Foucault, Michel: Un Diálogo sobre el Poder. Trad. M. Morey. Madrid: Alianza, 1985. - Dits et Écrits I, 1954-1975. Paris: Gallimard, 2001.

Sloterdijk, Peter: Kritik der zynischen Vernunft. Frankfurt a.M.: Suhrkamp, 1983.

- Nicht gerettet. Frankfurt a.M.: Suhrkamp, 2001. Sphären. Frankfurt a.M.: Suhrkamp, 1998-2004. Im Weltinnenraum des Kapitals. Frankfurt a.M.: Suhrkamp, 2005.

Sloterdijk, Peter y Peter Weibel: Der ästhetische Imperativ: Schriften zur Kunst. Hamburg: Philo \& Philo Fine Arts, EVA, 2007.

Palabras clave: verdad; desocultamiento; Sloterdijk; Foucault; Heidegger. Recibido: mayo de 2008; aceptado: julio de 2008. 